\title{
Yatan Hastalarda Çeşitli Klinik Örneklerden İzole Edilen Acinetobacter baumanniii Suşlarının Antibiyotiklere Direnç Durumlarının İncelenmesi*
}

\author{
Mustafa BEHÇET 國, Fatma AVCIOĞLU [i] ${ }^{1}$, Şeyda KARABÖRK ${ }^{1}{ }^{1}$, \\ Muhammet Güzel KURTOĞLU ${ }^{1}$
}

ÖZ

Amaç: Son yıllarda geniş spektrumlu antibiyotiklerin yaygın kullanımı nedeniyle Acinetobacter baumanniii (A. baumannii)'nin ilaç direncindeki hızlı artışlar dünya çapında acil bir sorun haline gelmiştir. Bu çalışmada klinik örneklerden izole edilen A. baumannii suşlarının antimikrobiyal direnç durumlarının saptanarak ampirik tedavi ve antibiyotik kullanım politikalarına katkıda bulunulması amaçlanmıştır.

Gereç ve Yöntemler: Ocak 2015-Aralık 2017 tarihleri arasında klinik örneklerden izole edilen toplam 136 A. baumannii suşu retrospektif olarak incelenmiştir. Gönderilen örnekler \%5 koyun kanlı agar, EMB (Eosin Metilen Blue) agar ve çikolatamsı agar besiyerlerine, kan ve steril vücut sıvıları ise Bactec 9120 (Becton Dickinson, ABD) kan kültür sistemine ait sişelere ekilmiştir. Bakteri tanımlaması ve antimikrobiyal duyarlılık testleri için konvansiyonel yöntemler ve Phoenix (Becton Dickinson, ABD) tam otomatik bakteri tanımlama sistemi kullanılmıştır.

Bulgular: A. baumannii suşları en sık yoğun bakımlardan 109 (\%80.1) ve solunum yolu örneklerinden 98 (\%72) izole edilmiştir. Antibiyotik direnç oranları kolistin için \%5.9, amikasin için \%39.7, trimetoprim/sülfametaksazol için \%73.5, gentamisin için \%81.6, meropenem için \%82.4, imipenem, siprofloksasin için \%83.1 ve seftazidim için \%83.8, sefepim, piperasilin, piperasilin/tazobaktam \%85.3 olarak saptanmıştır.

Sonuç: Kolistin ve amikasin dışındaki antibiyotiklere direnç oranlarının yüksek oranda saptanması (>\%70) özellikle yoğun bakımlarda tedavi gören ve ciddi solunum yolu enfeksiyonu olan hastalarda ampirik antibiyotik tedavi uygulamalarının çok dikkatli şekilde yapılması gerektiğini düşündürmüştür.

Anahtar Kelimeler: Acinetobacter baumanniii; antibiyotik direnci.

\section{Investigation of the Resistance Rates of Antibiotics in Acinetobacter baumannii Strains Isolated from Various Clinical Samples in Inpatients}

\begin{abstract}
Aim: Due to the widespread use of broad spectrum antibiotics in recent years, rapid increases in drug resistance of Acinetobacter baumanni (A. baumannii) have become an urgent problem worldwide. In this study, it was aimed to determine the antimicrobial resistance patterns of $A$. baumannii strains isolated from clinical samples and to contribute to empirical treatment and antibiotic use policies.

Material and Methods: A total of 136 A. baumannii strains isolated from clinical specimens between January 2015 and December 2017 were retrospectively analyzed. The samples were inoculated in 5\% sheep blood, EMB (Eosin Methylene Blue) and chocolate agar media, while blood and sterile body fluids were inoculated in Bactec 9120 blood culture system. Bacterial identification and antimicrobial susceptibility testing were performed using conventional methods and Phoenix (Becton Dickinson, USA) fully automated bacteria identification system.

Results: A. baumannii strains were most frequently isolated from the intensive care units 109 isolates (80.1\%) and from the respiratory tract samples 98 isolates (72\%). Antibiotic resistance rates were found to be 5.9\% for colistin, 39.7\% for amikacin, $73.5 \%$ for trimethoprim/sulfamethoxazole, $81.6 \%$ for gentamicin, $82.4 \%$ for meropenem, $83.1 \%$ for imipenem, ciprofloxacin, 83.8\% for ceftazidime and 85.3\% from cefepime, piperacillin, piperacillin/tazobactam.
\end{abstract}

1 Bolu Abant İzzet Baysal Üniversitesi, Tıp Fakültesi, Tıbbi Mikrobiyoloji A.D., Bolu, Türkiye

*Bu çalışma 4-8 Kasım 2018 tarihleri arasında Antalya'da düzenlenen Uluslararası XXXVIII. Türk Mikrobiyoloji Kongresinde poster bildiri olarak sunulmuştur. 
Conclusion: High rates of resistance to antibiotics other than colistin and amikacin (>70\%) suggested that empirical antibiotic treatment should be performed very carefully especially in intensive care unit patients with severe respiratory tract infections.

Keywords: Acinetobacter baumanniii; antibiotic resistance.

\section{GÍRIŞ}

Acinetobacter baumanniii (A. baumannii) zorunlu aerobik, non-fermentatif, hareketsiz, katalaz pozitif, oksidaz ve Gram negatif bir mikroorganizmadır (1). Sağlıklı insanların normal cilt florasında bulunmakta olup uzun süreli hastanede kalma, yoğun bakım ünitesi, mekanik ventilasyon, antimikrobiyal kullanımı, invaziv cerrahi girişimler ve altta yatan ciddi hastalıklar çoklu ilaca dirençli Acinetobacter türlerinde kolonizasyon veya enfeksiyon gelişme riskine neden olmaktadır. $A$. baumannii, özellikle ventilatör ilişkili solunum yolu enfeksiyonlarına, takiben bakteriyemiye, daha az sıklıkta da idrar yolu, cerrahi yara, merkezi sinir sistemi, deri ve göz enfeksiyonlarına neden olmaktadır $(2,3)$.

Son yıllarda geniş spektrumlu antibiyotiklerin yaygın kullanımı nedeniyle A. baumannii’ye karşı ilaç direncinde meydana gelen hızlı artışlar dünya çapında acil bir sorun haline gelmiştir (4).

Bu çalışmada Ocak 2015-Aralık 2017 tarihleri arasında hastanemizde yatan hastalardan Mikrobiyoloji Laboratuvarına gönderilen çeşitli klinik örneklerden izole edilen A. baumannii suşlarının antimikrobiyal direnç durumlarının saptanarak ampirik tedaviye ve antibiyotik kullanım politikalarına katkıda bulunulması amaçlanmıştır.

\section{GEREÇ VE YÖNTEMLER}

Ocak 2015-Aralık 2017 tarihleri arasında hastanede yatan hastalardan Mikrobiyoloji Laboratuvarına gönderilen çeşitli klinik örneklerden izole edilen toplam $136 \mathrm{~A}$. baumannii suşu retrospektif olarak incelenmiştir. Her hastadan üretilmiş olan tek suş çalışmaya dahil edilmiştir. Kan ve steril vücut siviları Bactec 9120 (Becton Dickinson, $\mathrm{ABD}$ ) kan kültür sistemine ait şişelere ekilerek $37{ }^{\circ} \mathrm{C}$ 'de en fazla yedi gün süreyle inkübe edilmiştir. Bakteri tanımlaması ve antimikrobiyal duyarlılık testleri klasik yöntemler ve Phoenix (Becton Dickinson, ABD) tam otomatik bakteri tanımlama sistemi kullanılarak yapılmıştır. Gönderilen diğer örnekler ise $\% 5$ koyun kanlı, EMB (Eosin Metilen Blue) ve çikolatamsı agar (RTA, Tükiye) besiyerlerine ekilmiş olup aerobik ortamda $35{ }^{\circ} \mathrm{C}$ 'de 24 saat etüvde inkübe edilmiştir. Kolistin, amikasin, trimetoprim / sülfametaksazol, gentamisin, meropenem, imipenem, ve siprofloksasin için EUCAST (European Committee on Antimicrobial Susceptibility Testing), seftazidim, sefepim, piperasilin ve piperasilin/tazobaktam için CLSI (The Clinical and Laboratory Standards Institute) kriterleri uygulanmıştır. Orta duyarlı suşlar dirençli olarak kabul edilmiştir $(5,6)$. $\mathrm{Bu}$ çalışma için yerel etik kurul izni 2018/211 numarası ile alınmıştır.

\section{İstatistiksel Analiz}

İstatistiksel olarak veriler frekans ve yüzdelerle özetlenmiştir. Yüzde değerleri arasındaki farkları incelemek için tek örneklem Ki-kare testi kullanılmıştır.
İstatistiksel testler için anlamlılık düzeyi 0.05 kabul edilmiştir.

\section{BULGULAR}

Toplam 136 A. baumannii suşunun 83'ü (\%61) erkek, 53’ü (\%39) kadın hastalardan izole edilmiştir. A. baumannii suşunun görülme sıklığı kadın ve erkeklerde istatistiksel olarak anlamlı derecede farklıdır $(\mathrm{p}=0.010$, Grafik 1). Hastaların yaşları 22-95 arasında olup yaş ortalaması $68,23 \pm 14,83$ olarak bulunmuştur.

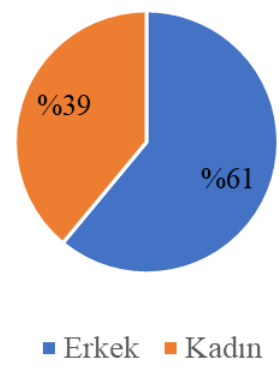

Grafik 1. Cinsiyete göre A. baumannii suşlarının dağılımı

A. baumannii suşları en fazla yoğun bakımlardan gönderilen klinik örneklerden 109 (\%80.1) izole edilirken diğer suşlar enfeksiyon hastalıkları servisi 12 (\%8.8), gögüs hastalıkları servisi $9 \quad(\% 6.6)$ ve cerrahi servislerinden $6 \quad(\% 4.4)$ laboratuvarımıza gönderilen örneklerden izole edilmiştir. A. baumannii suşlarının görülme sıklığ 1 kliniklere göre istatistiksel olarak anlamlı şekilde farklıdır $(\mathrm{p}<0.001$, Grafik 2). A. baumannii suşları en sık sırasıyla solunum yolu örnekleri 98 (\%72), yara $17(\% 12.5)$, idrar $14(\% 10.3)$, steril vücut sıvıları 5 $(\% 3.7)$ ve kan $2(\% 1.5)$ örneklerinden izole edilmiştir. $A$. baumannii suşlarının görülme sıklığı örneklere göre istatistiksel olarak anlamlı şekilde farklıdır $(\mathrm{p}<0.001$, Grafik 3).

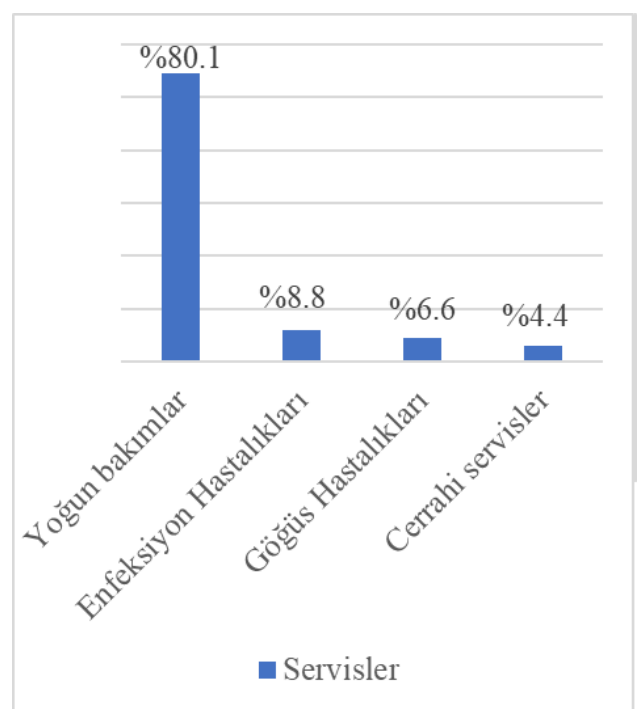

Grafik 2. A. baumannii suşlarının izole edildiği klinikler 


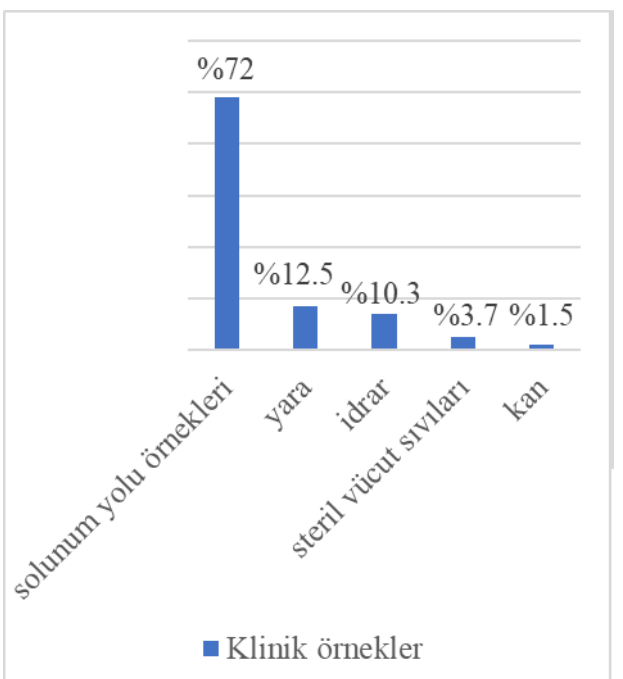

Grafik 3. A. baumannii suşlarının izole edildiği klinik örnekler

Antibiyotik direnç oranı en az kolistin (\%5.9) olarak saptanmıştır. Amikasin' için \%39.7 trimetoprim/sülfametaksazol için $\% 73.5$ ve diğer antibiyotiklere karşı direnç oranları Tablo 1'de gösterilmiştir. Tüm antibiyotikler için dirençli olan ve olmayan örnek sayıları anlamlı şekilde farklı bulunmuştur.

Tablo 1. A. baumannii antibiyotik direnç oranları

\begin{tabular}{|l|c|c|c|}
\hline Antibiyotik & $\mathbf{n}$ & $\begin{array}{c}\text { Direnç } \\
\text { oranı (\%) }\end{array}$ & $\mathbf{p}$ \\
\hline Kolistin & 8 & 5.9 & $<0.001$ \\
\hline Amikasin & 54 & 39.7 & 0.016 \\
\hline TMP-SXT & 100 & 73.5 & $<0.001$ \\
\hline Gentamisin & 111 & 81.6 & $<0.001$ \\
\hline Meropenem & 112 & 82.4 & $<0.001$ \\
\hline İmipenem & 113 & 83.1 & $<0.001$ \\
\hline Siprofloksasin & 113 & 83.1 & $<0.001$ \\
\hline Seftazidim & 114 & 83.8 & $<0.001$ \\
\hline Sefepim & 116 & 85.3 & $<0.001$ \\
\hline Piperasilin/tazobaktam & 116 & 85.3 & $<0.001$ \\
\hline Piperasilin & 116 & 85.3 & $<0.001$ \\
\hline
\end{tabular}

TMP-SXT: Trimetoprim/sülfametaksazol

\section{TARTISSMA VE SONUC}

Acinetobacter spp. çeşitli çevresel ortamlarda, sıklıkla kullanılan mekanik aletlerin yüzeylerinde, hastalarda ve personelde kolonize olarak uzun süre canlılıklarını sürdürebilmektedir. Özellikle yoğun bakım ünitelerinde yatan hastaların çoğunlukla geniş spektrumlu antibiyotik tedavisi almaları risk faktörü oluşturmakta ve sıklıkla bu birimlerden izole edilmelerine neden olmaktadır (7).

Ülkemizde yapılan çeşitli çalışmalarda A. baumannii yoğun bakımlarda \%29-\%92.9 oranlarında izole edilmiştir (8-15). Çalışmamızda yoğun bakımlardan izole edilen \%80.1'lik oran bu aralık içerisinde yer almakta ve Balıkesir' de saptanan \%83.4'lük oranla yakın benzerlik göstermektedir (13).

Hastane ortamında ve yüzeylerde uzun süreler boyunca kalabilme yeteneklerinden dolayı pnömoni, bakteriyemi, menenjit, idrar yolu enfeksiyonu ve yara enfeksiyonunu içeren geniş bir enfeksiyon yelpazesine ve çoklu salgınlara neden olmaktadır (16). Çalışmamızda $A$. baumannii en s1k solunum yolu örneklerinden (\%72) izole edilmiş olup ülkemizde yapılan diğer çalışmalarla (\%39-64.6) uyumlu görünmektedir $(12-15,18,19)$.

A. baumannii enfeksiyonlarında genellikle antipsöudomonal penisilinler, anti-psöudomonal sefalosporinler, monobaktamlar, aminoglikozidler, florokinolonlar, karbapenemler, polimiksinler, sulbaktam ve glisilsiklinler tercih edilmektedir. Ayrıca kombinasyon tedavileri de önerilmektedir. Yapılan surveyans çalışmalarında sık kullanılan antibiyotikler için direnc oranlarının yıllar içerisinde gittikçe arttı̆̆ bildirilmektedir $(17,20)$.

Ülkemizde yapılan çeşitli çalışmalarda A. baumannii suşlarında imipenem direnci \%30-92, meropenem direnci \%31.8-92 oranlarında bildirilmiştir. (812,19,22-24). Yillar içerisinde imipenem ve meropenem direncinin artış oranını incelediğimizde Savcı ve ark. (12) imipenem için 2009 yılına kadar \%0 olan direnç oranının 2012 yılında \%96’ya, Güven ve ark. (25) ise 2008 yılında imipenem ve meropenem için direnç oranlarının sirasıyla \%54, \%73.5 iken 2011 y1lında ise \%98.9, 98.9' a yükseldiğini bildirmişlerdir. OECD üyesi ülkeler için yapılan bir çalışmada imipenem direnci 2000-2005 y1llarında ortalama \%23.8 (9.7-38.0), 20062010 yillarında \%51.6 (34.4-68.9), 2011-2016 yıllarında ise \%73.9 (54.8-95.6) olarak gittikçe artan oranlarda bildirilmiştir (21). Gerek ülkemizde gerekse yurt dışında yapılan farklı çalışmalara uyumlu olarak çalışmamızda da meropenem (\%82.4) ve imipenem (\%83.1) direnç oranları yüksek bulunmuştur.

Ülkemizde yapılan çeşitli çalışmalarda direnç oranları sefepim için \%93-99.6 seftazidim için \%89-98, piperasilin için \%84-96.7, piperasilin/tazobaktam için \%84-97, siprofloksasin için \%76-94.5 ve trimetoprim/sülfametaksazol için \%64-91.7 (11$15,18,19,22-27)$ olarak bildirilirken yurt dışında yapılan farklı çalışmalarda ise direnç oranları sefepim için \%51100, seftazidim için \%65.4-95.5, piperasilin/tazobaktam için \%61-100, siprofloksasin için \%74.94-95.9 ve trimetoprim/sülfametaksazol için de \%55.3-71.28 (21,2830) oranlarda bildirilmiştir. Çalışmamızda trimetoprim/sülfametaksazol için \%73.5 ve sefepim, seftazidim, piperasilin, piperasilin/tazobaktam ve siprofloksasin için \%80' in üzerinde direnç saptanması bu çalışmalar ile benzerlik göstermektedir.

Aminoglikozidler ile ilgili ülkemizde yapılan çalışmalarda direnç oranları gentamisin için \%52.2-98, amikasin için \%38.9-81 oranlarında bildirilmiştir (1115,19,22-27). Yurt dişında 2011-2016 yilları arasında yapılan çalışmalarda amikasin için direnç oranları \%40.4\%92.7 olarak bildirilmiştir (21). Çalışmamızda gentamisine karşı \%81.6 gibi yüksek düzeyde direnç gözlenirken amikasin' e karşı daha az oranda (\%39.7) direnç gözlenmiştir.

Karbapenem dirençli A. baumannii enfeksiyonlarını tedavi etmek için kolistin kullanımının artmasıyla birlikte bu ilaca karşı da direnç ortaya çıkmıştır (31). Ülkemizde yapılan çalışmalarda kolistin direnci \%0-7.2 arasında değişmektedir $(8,11-14,19,22,23,27)$. ABD' de yayımlanan bir sürveyans raporunda kolistine \%5.3, 2011-2016 yıllarına OECD ülkelerinde $\% 0-2.9$ ve OECD dışındaki ülkelerde ise \%0-3.7 arasında direnç oranları 
bildirilmiștir (21,28). Çalıșmamızda kolistin'e karşı görülen \%5.9'luk direnç oranı bu çalışmalarla benzerdir. Sonuç olarak A. baumannii suşları hastanemizde en sık yoğun bakımda yatan hastalardan ve solunum yolu örneklerinden izole edilmiştir. Kolistin ve amikasin dıșındaki antibiyotiklere direnç oranlarının yüksek oranda saptanması $(>\% 70)$ özellikle yoğun bakımlarda tedavi gören ve ciddi solunum yolu enfeksiyonu olan hastalarda ampirik antibiyotik tedavi uygulamalarının çok dikkatli şekilde yapılması gerektiğini düşündürmüştür.

\section{KAYNAKLAR}

1. Sotgiu G. Outbreak of multidrug-resistant Acinetobacter baumanniii in an intensive care unit. New Microbiol. 2014; 37(2): 185-91.

2. Forster DH, Daschner FD. Acinetobacter species as nosocomial pathogens. Eur J Clin Microbiol Infect Dis. 1998; 17(2): 73-7.

3. Eliopoulos GM, Maragakis LL, Perl TM. Acinetobacter baumanniii: Epidemiology, antimicrobial resistance, and treatment options. Clin Infect Dis. 2008; 46(8): 1254-63.

4. Gao L, Lyu Y, Li Y. Trends in drug resistance of Acinetobacter baumanniii over a 10-year period: Nationwide data from the China surveillance of antimicrobial resistance program. Chin Med J (Engl). 2017; 130(6): 659-64.

5. The European Committee on Antimicrobial Susceptibility Testing. Breakpoint tables for interpretation of MICs and zone diameters. Version 4.0, 2014. Available from: http://www.eucast.org.

6. The Clinical and Laboratory Standards Institute (CLSI). Performance standards for antimicrobial susceptibility testing; twenty-fourth informational supplement. M100-S24 Wayne, PA. 2014; 34(1): 623.

7. Jung JY, Park MS, Kim SE, Park BH, Son JY, Kim $E Y$, et al. Risk factors for multi-drug resistant Acinetobacter baumanniii bacteremia in patients with colonization in the intensive care unit. BMC Infect Dis. 2010; 10: 1-11. doi: 10.1186/1471-2334-10-228.

8. Iraz M, Ceylan A, Akkoyunlu Y. Çeşitli klinik örneklerden izole edilen Acinetobacter türlerinde antibiyotik direnç oranlarının incelenmesi. Ankem Derg. 2012; 26(2): 80-5.

9. Mansur A, Kuzucu C, Ersoy Y, Yetkin F. İnonu Üniversitesi Turgut Özal Tıp Merkezinde 2008 yllında yatan hastalardan izole edilen Acinetobacter suşlarının antibiyotik duyarlılıkları. Ankem Derg. 2009; 23(4): 177-81.

10. Ozdem B, Gurelik FC, Celikbilek N, Balıkc1 H, Acıkgoz ZC. Çeşitli klinik örneklerden 2007-2010 yıllarında izole edilen Acinetobacter türlerinin antibiyotik direnç profili. Mikrobiyol Bül. 2011; 45(3): 526-34.

11. Bayram Y, Gultepe B, Bektaş A, Parlak M, Guducuoğlu H. Çeşitli klinik örneklerden izole edilen Acinetobacter baumanniii suşlarının antibiyotiklere direnç oranlarının araştırılması. Klimik Derg. 2013; 26(2): 49-53.

12. Savcı Ü, Özveren G, Yenişehirli G, Bulut Y, Özdaş S. In-vitro susceptibility of Acinetobacter baumanniii strains isolated from clinical specimens. Turk J Clin Lab. 2015; 6(1): 24-9.

13. Şafak B, Kılınç O, Tunç N. Klinik örneklerden izole edilen Acinetobacter baumanniii suşlarının antibiyotik duyarlılık oranlarının incelenmesi (20102016). FLORA. 2016; 21(2): 77-81.

14. Korkmaz P, Çağlan FÇ, Aykın N, Alpay Y, Güldüren $\mathrm{HM}$, Bilgili $\mathrm{H}$, et al. Antibiotic resistance in Acinetobacter baumanniii strains isolated from nosocomial infections. J Clin Anal Med. 2015; 6(3): 394-7.

15. Kurtoğlu MG, Opuş A, Kaya M, Recep Keşli R, Güzelant A, Yüksekkaya Ş. Bir eğitim ve araştırma hastanesinde klinik örneklerden izole edilen Acinetobacter baumanniii suşlarında antibakteriyel direnç (2008-2010). Ankem Derg. 2011; 25(1): 35-41.

16. Manchanda V, Sanchaita S, Singh NP. Multidrug resistant Acinetobacter. J Glob Infect Dis. 2010; 2(3): 291-304.

17. Xu T, Xia W, Rong G, Pan S, Huang P, Gu B. A 4year surveillance of antimicrobial resistance patterns of Acinetobacter baumannii in a university-affiliated hospital in China. J Thorac Dis. 2013; 5(4): 506-12.

18. Özseven AG, Çetin ES, Arıdoğan BC. Çeşitli klinik örneklerden izole edilen Acinetobacter baumanniii suşlarının antibiyotik direnç profilleri. Türk Mikrobiyol Cem Derg. 2012; 42(2): 55-60.

19. Dede B, Kadanalı A, Karagöz G, Çomoğlu Ş, Bektaşoğlu MF, Yücel FM. Yoğun bakım ünitesinde izole edilen Acinetobacter baumanniii suşlarının antibiyotik dirençlerinin araştırılması. Med J Bakirkoy. 2013; 9(1): 20-3.

20. Evren E, Gocmen JS, Demirbilek M, Alışkan HE. Çeşitli klinik örneklerden izole edilen çoklu ilaca dirençli Acinetobacter baumanniii suşlarının imipenem, meropenem, kolistin, amikasin ve fosfomisin duyarlılıkları. GMJ. 2013; 24(1): 1-4.

21. Xie R, Zhang XD, Zhao Q, Peng B, Zheng J. Analysis of global prevalence of antibiotic resistance in Acinetobacter baumanniii infections disclosed a faster increase in OECD countries. Emerg Microbes Infect. 2018; 7(1): 1-10.

22. Özdemir M, Erayman İ, Gündem NS, Baykan M, Baysal, B. Hastane infeksiyonu etkeni Acinetobacter suşlarının çeşitli antibiyotiklere duyarlılıklarının araştırılması. Ankem Derg. 2009; 23(3): 127-32.

23. Gözütok F, Sarıüzel FM, Çelik İ, Berk E, Aydın B, Güzel D. Hastane infeksiyonu etkeni Acinetobacter baumanniii suşlarının antimikrobiyal direnç oranlarının araştırılması. Ankem Derg. 2013; 27(1): 7-12.

24. Aral M, Doğan S, Paköz NİE. Çeşitli klinik örneklerden izole edilen Acinetobacter baumanniii suşlarının antibiyotiklere direnç oranlarının araştırılması. Ankem Derg. 2010; 24(4): 215-9.

25. Güven T, Y1lmaz G, Güner HR, Kalem AK, Eser F, Taşyaran MA. Increasing resistance of nosocomial Acinetobacter baumanniii: Are we going to be defeated? Turk J Med Sci. 2014; 44(1): 73-8.

26. Kirişçi Ö, Özkaya E, Çalışkan A, Özden S, Alkış Koçtürk S. Klinik örneklerden izole edilen Acinetobacter türlerinde direnç profilinin incelenmesi. Ankem Derg. 2013; 27(3): 140-6. 
27. Kalem F, Ertuğrul Ö, Türk Dağı H. Çeşitli klinik örneklerden izole edilen Acinetobacter baumanniii suşlarında antibiyotik direnci. Abant Med J. 2017; 6(1): 20-5.

28. Zilberberg MD, Kollef MH, Shorr AF. Secular trends in Acinetobacter baumanniii resistance in respiratory and blood stream specimens in the United States, 2003 to 2012: A survey study. J Hosp Med. 2016; 11(1): 21-6.

29. Chen LK, Kuo SC, Chang KC, Cheng CC, Yu PY, Chang $\mathrm{CH}$, et al. Clinical Antibiotic-resistant Acinetobacter baumanniii strains with higher susceptibility to environmental phages than antibioticsensitive strains. Scientific reports. 2017; 7(1): 6319.

30. Adams-Haduch JM, Paterson DL, Sidjabat HE, Pasculle AW, Potoski BA, Muto CA, et al. Genetic basis of multidrug resistance in Acinetobacter baumanniii clinical isolates at a tertiary medical center in Pennsylvania. Antimicrob Agents. Chemother. 2008; 52(11): 3837-43.

31. Dortet L, Potron A, Bonnin RA, Plesiat P, Naas T, Filloux A, et al. Rapid detection of colistin resistance in Acinetobacter baumanniii using MALDI-TOFbased lipidomics on intact bacteria. Scientific Reports. 2018; 8(1): 16910. 